\title{
REVIEW ON THE ELABORATION AND MORFO-STRUCTURAL CHARACTERIZATION OF IRON OXIDE FOR CATALYTIC APPLICATIONS
}

\author{
Ecaterina Magdalena MODAN, Adriana-Gabriela PLĂIASU \\ University of Pitesti, Pitesti, Romania \\ e-mail: ecaterina.modan@upit.ro,gabriela.plaiasu@upit.ro
}

\begin{abstract}
Magnetite, $\mathrm{Fe}_{3} \mathrm{O}_{4}$ exhibits the strongest magnetism of transition metal oxides. Hematite, $\alpha-\mathrm{Fe}_{2} \mathrm{O}_{3}$ being the most stable oxide and semiconductor type $n$ under environmental conditions, can be widely used in catalysts, pigments and gas sensors. Iron oxide nanoparticles $\left(\mathrm{Fe}_{3} \mathrm{O}_{4}\right.$ and $\left.\gamma-\mathrm{Fe}_{2} \mathrm{O}_{3}\right)$ with superparamagnetic properties and low toxicity, are particularly useful for catalytic applications especially in the medical field. For these applications, the $\mathrm{Fe}_{3} \mathrm{O}_{4}$ and $\gamma-\mathrm{Fe}_{2} \mathrm{O}_{3}$ nanoparticles are usually smaller than $20 \mathrm{~nm}$, where they have superparamagnetic properties, i.e. a high magnetic saturation moment and almost zero coercivity. This review presents the theoretical concepts of the structure properties of this oxide and the elaboration methods that make iron oxide the ideal candidate for catalytic applications.
\end{abstract}

KEYWORDS: iron oxide, hematite, magnetite, maghemite, properties, morphologies, elaboration

\section{Introduction}

Iron oxide is a naturally occurring mineral compound that has several crystalline structures and also different structural and magnetic properties [1]. The main crystalline forms of this mineral are: hematite $\left(\alpha-\mathrm{Fe}_{2} \mathrm{O}_{3}\right)$; magnetite $\left(\mathrm{Fe}_{3} \mathrm{O}_{4}\right)$; maghemite $(\gamma$ $\left.\mathrm{Fe}_{2} \mathrm{O}_{3}\right)$ [2].

Hematite $\left(\alpha-\mathrm{Fe}_{2} \mathrm{O}_{3}\right)$ is the mineral form of iron oxide III. It is found in soils and has different colours from black to silver-grey, maroon to reddish or even red. Hematite $\left(\alpha-\mathrm{Fe}_{2} \mathrm{O}_{3}\right)$ can be widely used in catalysts, pigments and gas sensors, as it is the most stable iron oxide and n-type semiconductor [3]. Hematite is easier to synthesize than other forms of oxide, as it is the end product of other forms of iron oxide transformation and is also extremely stable under environmental conditions. It can also be used as a basic material for the synthesis of magnetite $\left(\mathrm{Fe}_{3} \mathrm{O}_{4}\right)$ and maghemite $\left(\gamma-\mathrm{Fe}_{2} \mathrm{O}_{3}\right)$ [4]. As shown in Figure 1 (a), $\alpha-\mathrm{Fe}_{2} \mathrm{O}_{3}$ has a rhombohedral structure. Magnetite $\left(\mathrm{Fe}_{3} \mathrm{O}_{4}\right)$ is a magnetic iron oxide nanoparticle known as black iron oxide, magnetic iron ore. Among the transition metal oxides, it exhibits the strongest magnetism [5]. $\mathrm{Fe}_{3} \mathrm{O}_{4}$ has the spinel structure, exemplified in Figure 1. $\mathrm{Fe}_{3} \mathrm{O}_{4}$ differs from most other iron oxides in that it contains both divalent and trivalent iron. Thus, $\mathrm{Fe}_{3} \mathrm{O}_{4}$ can be both a n-type and pmagnetic semiconductor $\left(\mathrm{Fe}_{3} \mathrm{O}_{4}\right)$, at room temperature, having ferromagnetic properties, which differs from other forms of iron oxides, because its structure has both divalent and trivalent iron. However, $\mathrm{Fe}_{3} \mathrm{O}_{4}$ has the lowest resistivity among iron oxides due to low bandgap (0.1 eV) [6].

Maghemite $\left(\gamma-\mathrm{Fe}_{2} \mathrm{O}_{3}\right)$ is one of the magnetic forms of iron oxides and has a brown colour. The structure of the maghemite is a cubic spinel structure, and for this reason it can be regarded as a magnetite with $\mathrm{Fe}^{2+}$ deficiency. Therefore, maghemite can be considered as completely oxidized magnetite and is a n-type semiconductor with a $2.0 \mathrm{eV}$ band [7].

The crystalline structures of iron oxide are exemplified in Fig. 1 [8].

Due to their superparamagnetic properties and low toxicity, iron oxide nanoparticles $\left(\mathrm{Fe}_{3} \mathrm{O}_{4}\right.$ and $\gamma$ $\mathrm{Fe}_{2} \mathrm{O}_{3}$ ) are particularly interesting for biomedical applications, such as NMR imaging. For these applications, the $\mathrm{Fe}_{3} \mathrm{O}_{4}$ and $\gamma-\mathrm{Fe}_{2} \mathrm{O}_{3}$ nanoparticles are usually smaller than $20 \mathrm{~nm}$, have superparamagnetic properties, i.e. high magnetic saturation moment and almost zero coercivity. 

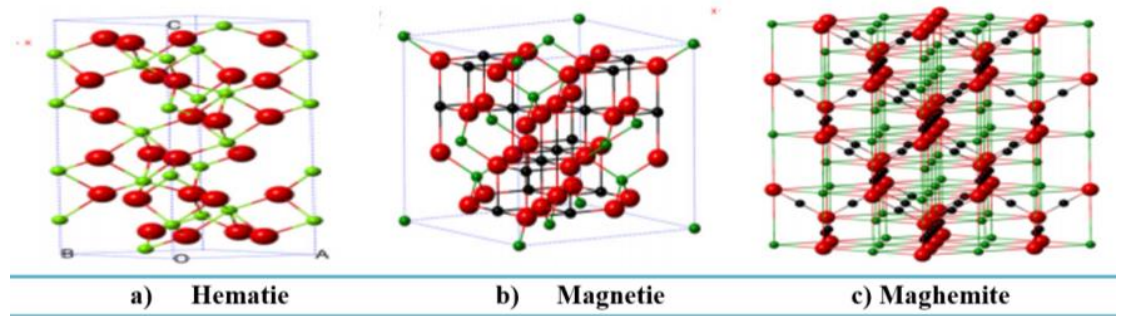

Fig. 1. Crystal structures of hematite, magnetite and maghemite $\left(\bullet-\mathrm{Fe}^{2+}, \mathrm{O}-\mathrm{Fe}^{3+}, \mathrm{O}-\mathrm{O}^{2-}\right)[8]$

Magnetite is a very promising iron oxide due to its proven biocompatibility. Magnetic nanoparticles of iron oxides have excellent applications in drug delivery to tumours as well as anticancer agents [914]. Magnetite and hematite have been used as catalysts for a number of industrially important reactions, including desulfurization of natural gas synthesis, high temperature water change reaction and in the Haber process. They are also involved in the oxidation of alcohols and the large-scale manufacture of butadiene [10-16]. Maghemite has applications in data recording and storage [17]. All three forms of magnetic iron oxide are commonly used in synthetic pigments, paints, ceramics and porcelain [18]. In recent decades, special attention has been focused on the development of elaboration approaches to produce nanoparticles that are shape and size controlled, biocompatible and monodisperse for catalytic applications [19]. Various morphologies of iron oxide nanoparticles (nanospheres, plates, tetrahedrons, cubes, nanowires, nanotubes, nanoflowers, nanoins) have been developed according to different synthesis protocols and are exemplified in Figure 2 [20-21].
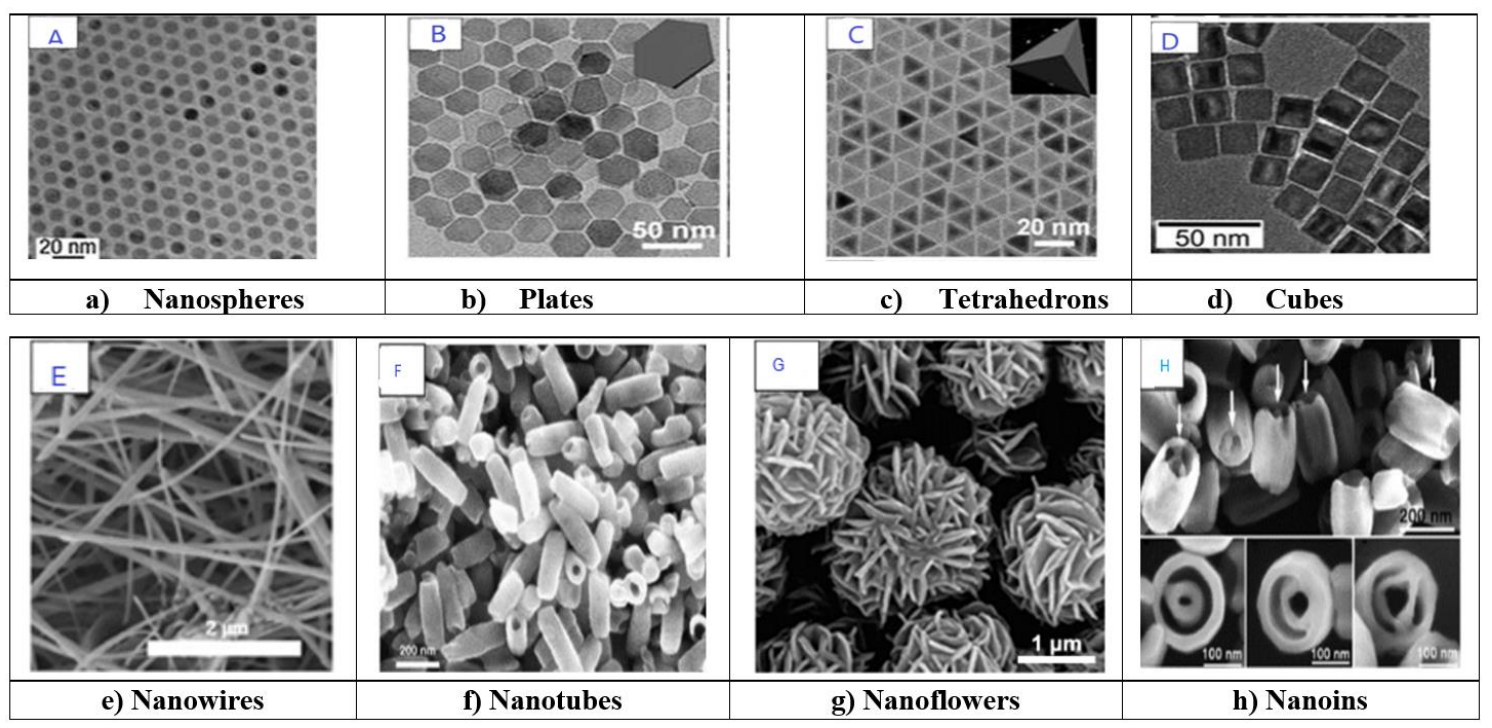

Fig. 2. Morphologies of iron oxide nanoparticles (a) nanospheres, (b) plates, $(c)$ tetrahedrons, $(d)$ cubes $(e)$ nanowires, $(f)$ nanotubes, $(g)$ nanoflowers, $(h)$ nanoins $[20,21]$

\section{Methods of elaboration}

\subsection{Precipitation method}

The most commonly used method for obtaining $\mathrm{Fe}_{\mathrm{x}} \mathrm{O}_{\mathrm{y}}$ is co-precipitation. The method consists of mixing precursors containing $\mathrm{Fe}^{2+} / \mathrm{Fe}^{3+}=1: 2$ in basic solutions at room temperature or at high temperature. The size and morphology of iron oxide nanoparticles depend on the type of salt used, chlorides, sulphates, nitrates, perchlorates, etc., the ratio of $\mathrm{Fe}^{2+} / \mathrm{Fe}^{3+}$ concentration, the reaction temperature, the $\mathrm{pH}$ value, the ionic resistance of the environment and the other reaction parameters (e.g. stirring speed, lowering rate of the basic solution). In 1981, the development of superparamagnetic iron oxide nanoparticles with controlled dimensions was reported by precipitation in basic environment of $\mathrm{FeCl}_{3}$ and $\mathrm{FeCl}_{2}$ salts by Massart and his collaborators. They observed the influence of the base used (ammonia, methylamine and sodium hydroxide), the $\mathrm{pH}$ value, the $\mathrm{Fe}^{2+} / \mathrm{Fe}^{3+}$ ratio on the reaction yield, the diameter and the 
polydispersity of the obtained nanoparticles. By adjusting these parameters, nanoparticles with sizes from $4.2 \mathrm{~nm}$ to $16.6 \mathrm{~nm}$ were obtained. XRD data revealed a rhombohedral (hexagonal) structure with space group R-3c in all samples. TEM and SEM confirmed the spherical morphology of precipitated synthesized iron oxide nanoparticles [23, 24]. Sun and Zeng developed magnetic nanoparticles of magnetite with variable dimensions from $3 \mathrm{~nm}$ to 20 $\mathrm{nm}$ in diameter by co-precipitating a stoichiometric mixture of $\mathrm{Fe}$ (II) and $\mathrm{Fe}$ (III) salts in a basic medium, sodium hydroxide or ammonium hydroxide. Both high-resolution TEM HRTEM and XRD were used to obtain information about nanoparticle structure $\left(\mathrm{Fe}_{3} \mathrm{O}_{4}\right)$. The spherical morphology with the size around $20 \mathrm{~nm}$ of iron oxide nanoparticles was determined by SEM [25].

Table 2. Reaction parameters and characterization of iron oxide nanoparticles obtained by coprecipitation method

\begin{tabular}{|c|c|c|c|c|c|c|}
\hline $\begin{array}{c}\text { Oxide } \\
\text { type }\end{array}$ & Precursor & $\begin{array}{l}\text { Hydrolysis } \\
\text { agent / } \\
\text { surfactant / } \\
\text { solvent }\end{array}$ & $\begin{array}{c}\text { Temperature } \\
\text { Time } \\
\text { pH }\end{array}$ & $\begin{array}{l}\text { Dimension/ } \\
\text { morphology }\end{array}$ & $\begin{array}{c}\text { Characterization } \\
\text { method }\end{array}$ & References \\
\hline $\mathrm{Fe}_{3} \mathrm{O}_{4}$ & $\begin{array}{l}\mathrm{FeCl}_{3} \cdot 6 \mathrm{H}_{2} \mathrm{O} \\
\mathrm{FeCl}_{2} \cdot 4 \mathrm{H}_{2} \mathrm{O}\end{array}$ & $\begin{array}{c}\mathrm{NH}_{3} \\
\mathrm{NaOH} \\
\mathrm{CH}_{3} \mathrm{NH}_{2}\end{array}$ & 25 & $\begin{array}{l}4.2-16.6 \mathrm{~nm} / \\
\text { spheres }\end{array}$ & XRD, SEM & {$[23,24]$} \\
\hline $\mathrm{Fe}_{3} \mathrm{O}_{4}$ & $\begin{array}{l}\mathrm{FeCl}_{3} \cdot 6 \mathrm{H}_{2} \mathrm{O} \\
\mathrm{FeCl}_{2} \cdot 4 \mathrm{H}_{2} \mathrm{O}\end{array}$ & $\begin{array}{l}\mathrm{NaOH} \\
\mathrm{NH}_{4} \mathrm{OH}\end{array}$ & $25^{\circ} \mathrm{C}$ & $\begin{array}{l}3-20 \mathrm{~nm} \\
\text { spheres }\end{array}$ & XRD, TEM & [25] \\
\hline $\mathrm{Fe}_{3} \mathrm{O}_{4}$ & $\mathrm{FeCl}_{2} \mathrm{FeCl}_{3}$ & $\mathrm{NaOH}$ & $\begin{array}{c}25^{\circ} \mathrm{C} \\
\mathrm{pH}=11-12\end{array}$ & $\begin{array}{l}8.5 \mathrm{~nm} / \\
\text { spheres }\end{array}$ & XRD, TEM & [26] \\
\hline $\mathrm{Fe}_{3} \mathrm{O}_{4}$ & $\begin{array}{l}\mathrm{FeCl}_{2} \cdot 6 \mathrm{H}_{2} \mathrm{O} \\
\mathrm{FeCl}_{2} \cdot 4 \mathrm{H}_{2} \mathrm{O}\end{array}$ & $\mathrm{NH}_{3}$ & $\begin{array}{c}25^{\circ} \mathrm{C} \\
60 \mathrm{~min} \\
\mathrm{pH}=1.5-9\end{array}$ & $\begin{array}{l}40 \mathrm{~nm} / \\
\text { spheres }\end{array}$ & SEM, TEM, XRD & [27-28] \\
\hline $\begin{array}{c}\alpha- \\
\mathrm{Fe}_{2} \mathrm{O}_{3}\end{array}$ & $\mathrm{FeCl}_{3} \cdot 6 \mathrm{H}_{2} \mathrm{O}$ & $\begin{array}{l}\mathrm{NaOH} \\
\mathrm{NH}_{4} \mathrm{OH}\end{array}$ & $\begin{array}{c}80^{\circ} \mathrm{C} \\
\mathrm{pH}=11\end{array}$ & $21-82 \mathrm{~nm}$ & SEM, TEM, XRD & [29] \\
\hline $\mathrm{Fe}_{3} \mathrm{O}_{4}$ & $\mathrm{FeCl}_{3} \cdot 6 \mathrm{H}_{2} \mathrm{O}$ & $\begin{array}{c}\mathrm{KI} \\
\mathrm{NH}_{3} \\
\mathrm{PVA}\end{array}$ & $\begin{array}{l}\text { Calcination } \\
250^{\circ} \mathrm{C}\end{array}$ & $\begin{array}{c}7.84 \mathrm{~nm} / \\
\text { spheres } \\
\mathrm{d}=6.3 \mathrm{~nm}, \\
1=46.2 / \\
\text { nanorods }\end{array}$ & SEM, TEM, XRD & [30] \\
\hline
\end{tabular}

Kang et al. have synthesized monodisperse, uniform, narrow-size nanoparticles of $\mathrm{Fe}_{3} \mathrm{O}_{4}$ by coprecipitation without surfactants, using iron chlorides with a molar ratio of $\mathrm{Fe}^{\mathrm{II}} / \mathrm{Fe}^{\mathrm{III}}=0.5$ to a $\mathrm{pH}=11-12$. XRD data revealed a cubic structure. The spherical morphology with the size around $8.5 \mathrm{~nm}$ of the iron oxide nanoparticles was determined SEM [26]. Ahn et al. have obtained magnetite by this method and demonstrated that different iron species (oxyhydroxide) compositions can result. Mainly, the composition and also the size of the magnetite strongly depend on the molar ratio $\mathrm{Fe}^{2+} / \mathrm{Fe}^{3+}$. The small values of the ratio $\mathrm{x}=\mathrm{Fe}^{2+} / \mathrm{Fe}^{3+}$ which is $\mathrm{x}$ less than 0.1 lead to the formation of goethite $[\mathrm{FeO}(\mathrm{OH})]$. For $\mathrm{x}=0.2$ and $\mathrm{x}=0.3$, the distinct phase of oxyhydroxide and the variable size of the nonstoichiometric magnetite were formed. However, the best-known molar ratio used is $\mathrm{x}=0.5$ producing homogeneous nanoparticles in size and composition. The morpho-structural characterization of the synthesized iron oxide hydroxide nanoparticles was performed by XRD, TEM, SEM. XRD data revealed an orthorhombic structure. The $40 \mathrm{~nm}$ spherical morphology of iron oxide nanoparticles was determined by SEM [27, 28].

Lassoued et al. have reported the elaboration of $\alpha-\mathrm{Fe}_{2} \mathrm{O}_{3}$ hematite nanoparticles by a simple chemical method of co-precipitation starting from the hexahydrated iron chloride precursor. They followed in the experiments the impact of the variation of the precursor concentration on the crystalline phase, the size and the morphology of $\alpha-\mathrm{Fe}_{2} \mathrm{O}_{3}$. The characteristics of the synthesized hematite nanoparticles were evaluated by XRD, TEM, SEM. XRD data revealed a rhombohedral (hexagonal) structure with space group R-3c in all samples. TEM 
and SEM were confirmed by the uniform spherical morphology. The result revealed that the particle sizes varied between $21 \mathrm{~nm}$ and $82 \mathrm{~nm}$ and the increase of the precursor concentration $\left(\mathrm{FeCl}_{3} \cdot 6 \mathrm{H}_{2} \mathrm{O}\right)$ was accompanied by an increase of the particle size of 21 $\mathrm{nm}$ for pure $\alpha-\mathrm{Fe}_{2} \mathrm{O}_{3}$ synthesized with $\left[\mathrm{Fe}^{3+}\right]=0.05 \mathrm{M}$ at $82 \mathrm{~nm}$ for pure $\alpha-\mathrm{Fe}_{2} \mathrm{O}_{3}$ synthesized with $\left[\mathrm{Fe}^{3+}\right]=$ $0.4 \mathrm{M}$ [29].

Instead of using two iron precursors, Khalil started from an aqueous solution of $\mathrm{Fe}^{3+}$ salt. The procedure consisted of mixing iron chloride with an aqueous solution of potassium iodide with a $3: 1$ molar ratio. Potassium iodide reduces iron salt. The mixture was hydrolyzed with $25 \%$ ammonia to obtain the black precipitate of magnetite. He obtained spherical magnetite nanocrystals with a diameter of $7.84 \mathrm{~nm}$, rods with a diameter of $6.3 \mathrm{~nm}$ and a length of $46.2 \mathrm{~nm}$. The morphology of $\mathrm{Fe}_{3} \mathrm{O}_{4}$ nanocrystals was examined with the scanning electron microscope and a transmission electron microscope with an acceleration voltage of $200 \mathrm{kV}$ [30].

Kirillov et al. have obtained magnetite nanoparticles by co-precipitating iron sulphate (II) and iron chloride (III) in the presence of citrate ions, at room temperature and in argon medium. By changing the molar concentration of citrate, it was possible to obtain nanoparticles of different sizes (from $10.5 \mathrm{~nm}$ to $4.4 \mathrm{~nm}$ ) demonstrated by scanning electron microscopy [31]. Table 2 shows the precursors, hydrolysis agents, surfactants, solvents, reaction conditions, dimensions and morphologies of iron oxides elaborated by coprecipitation method.

\subsection{Thermal decomposition}

Thermal decomposition is one of the most studied methods for the controlled elaboration of different types of nanoparticles. The elaboration of nanoparticles by thermal decomposition is based on the thermal decomposition of the various iron precursors (salts or complex combinations) in organic environment and at high temperature. As an organic medium, high boiling solvents and surfactants are used. The morphology and size of the elaborated nanoparticles can be influenced by the ratio between the reactants used in the reaction, the temperature and the reaction time [31].

Rockenberge et al. have developed $\gamma-\mathrm{Fe}_{2} \mathrm{O}_{3}$ with a size of $10 \mathrm{~nm}$ by thermal decomposition starting from the precursor of the iron-cupferon complex (Cup $=\mathrm{N}$-nitroso-phenylhydroxylamine- $\left.\mathrm{C}_{6} \mathrm{H}_{5} \mathrm{~N}(\mathrm{NO}) \mathrm{OH}\right)$ [32].

Shortly, the Hyeon-led group of researchers developed iron oxide nanoparticles using the thermal decomposition method based on heating a reaction mixture (precursor, solvent, and surfactants) to the reflux temperature of the solvent (typically chain hydrocarbons are used) such as 1-octadecen, 1eicosan, etc.). Monodisperse magnetite with a particle size of $12 \mathrm{~nm}$ was prepared starting from the ironoleate complex, oleic acid which was dissolved in $200 \mathrm{~g}$ of 1-octadecene at room temperature. The mixture was heated at $320{ }^{\circ} \mathrm{C}$ for $30 \mathrm{~min}$. When the reaction temperature reached $320{ }^{\circ} \mathrm{C}$, the initial solution that was transparent became black-brown. The resulting solution containing the nanocrystals was then cooled to room temperature. Iron oxide nanocrystals were separated by centrifugation and characterized by XRD and TEM [33].

Maity et al. have studied the influence of reaction time on the size of nanoparticles developed by the thermal decomposition method. To obtain magnetite, the authors started from a mixture of iron acetylacetonate, oleic acid and oleylamine. If the reaction was carried out at $300{ }^{\circ} \mathrm{C}$ for $30 \mathrm{~min}, 5 \mathrm{~nm}$ nanoparticles were synthesized. By increasing the reaction time to $2 \mathrm{~h}$, the size of the nanoparticles increased to $6 \mathrm{~nm}$ and after $24 \mathrm{~h}$ to $11 \mathrm{~nm}$. If the elaboration reaction of the magnetite nanoparticles took place at $330{ }^{\circ} \mathrm{C}$, varying the reaction time from $30 \mathrm{~min}$ to $7 \mathrm{~h}$, spherical nanoparticles from $7 \mathrm{~nm}$ to $11 \mathrm{~nm}$ were obtained, demonstrated by electron microscopy characterization of sweeps $[34,35]$.

Colvin et al have demonstrated the possibility of combining both precursor and particle synthesis in a single process, using $\mathrm{FeO}(\mathrm{OH})$ as an iron source. In this process, a mixture of $\mathrm{FeO}(\mathrm{OH})$, oleic acid and 1octadecene is heated for several hours, which results in the synthesis of nanoparticles with monodisperse magnetite. The particle size increases linearly as the molar ratio of oleic acid / $\mathrm{FeO}(\mathrm{OH})$ becomes larger. Also, by raising the temperature to $340{ }^{\circ} \mathrm{C}$, particles with dimensions larger than 20-30 nm were developed, but at higher temperature the particle size distribution is considerably affected. TEM microscopy of these nanocrystals demonstrates the high quality of the synthesized nanocrystals. XRD confirms the magnetite crystal structure of the obtained nanocrystals.

Another research for the development of magnetic nanoparticles of $4 \mathrm{~nm}$ size was proposed by Sun et al. who have heated a mixture of iron acetylacetonate, phenyl ether, 1,2-hexadecanediol, oleic acid and oleylamine at reflux for half an hour. The uniform magnetic nanoparticles were synthesized by the decomposition of the organometallic precursors in an organic medium and in the presence of a surfactant, such as oleic acid. Higher temperatures, higher iron concentrations have been shown to accelerate the reaction and induce smaller particles and the oleic acid coating appears to be responsible for very high saturation magnetization values, independent of particle size and decreasing 
coercivity values, with the reduction of the particle size [36].

Table 3 illustrates precursors, hydrolysis agents, reaction parameters, characterization methods, crystallite dimensions of iron oxides obtained by the thermal decomposition method.

Table 3. Precursors, hydrolysis agents, reaction parameters and characterization of iron oxide nanoparticles obtained by the thermal decomposition method

\begin{tabular}{|c|c|c|c|c|c|c|}
\hline $\begin{array}{c}\text { Oxide } \\
\text { type }\end{array}$ & Precursor & $\begin{array}{c}\text { Hydrolysis } \\
\text { agent } / \\
\text { surfactant } / \\
\text { solvent }\end{array}$ & Temperature & $\begin{array}{c}\text { Dimension/ } \\
\text { morphology }\end{array}$ & $\begin{array}{c}\text { Characterization } \\
\text { method }\end{array}$ & References \\
\hline $\mathbf{F e}_{3} \mathbf{O}_{4}$ & Iron cupferon & octylamine & $250-300^{\circ} \mathrm{C}$ & $10 \mathrm{~nm}$ & XRD, SEM & {$[32]$} \\
\hline $\mathbf{F e}_{3} \mathbf{O}_{4}$ & $\begin{array}{c}\text { Iron Oleat } \\
\text { Complex }\end{array}$ & $\begin{array}{c}\text { 1-octadecene } \\
\text { Oleic acid }\end{array}$ & $320^{\circ} \mathrm{C}$ & $12 \mathrm{~nm}$ & XRD, TEM & {$[33]$} \\
\hline $\mathbf{F e}_{3} \mathbf{O}_{4}$ & $\begin{array}{c}\text { Iron } \\
\text { acetylacetonate }\end{array}$ & $\begin{array}{c}\text { oleylamine } \\
\text { Oleic acid }\end{array}$ & $300-330^{\circ} \mathrm{C}$ & $7-11 \mathrm{~nm}$ & XRD, TEM & {$[34]$} \\
\hline $\mathbf{F e}_{3} \mathbf{O}_{4}$ & $\begin{array}{c}\text { Iron hydroxide } \\
\text { oxide }\end{array}$ & $\begin{array}{c}\text { Oleic acid } \\
\text { 1-octadecene }\end{array}$ & $340{ }^{\circ} \mathrm{C}$ & $20-30 \mathrm{~nm}$ & XRD, TEM & {$[35]$} \\
\hline $\boldsymbol{\gamma}-\mathbf{F e}_{2} \mathbf{O}_{3}$ & $\begin{array}{c}\text { Iron } \\
\text { acetylacetonate }\end{array}$ & $\begin{array}{c}\text { phenyl ether } \\
\text { of oleic acid } \\
\text { oleylamine }\end{array}$ & $265^{\circ} \mathrm{C}$ & $4 \mathrm{~nm}$ & XRD, TEM & {$[36]$} \\
\hline
\end{tabular}

\subsection{Sol-gel method}

Cui et al. were able to develop different iron oxide nanoparticles $\alpha-\mathrm{Fe}_{2} \mathrm{O}_{3}, \quad \gamma-\mathrm{Fe}_{2} \mathrm{O}_{3}$ and $\mathrm{Fe}_{3} \mathrm{O}_{4}$ almost monodisperse through a medium-temperature sol-gel route. The formation of the various final iron oxide structures depends only on the drying process. Through TEM analysis, Cui et al. have observed 4.9 $\mathrm{nm} \mathrm{Fe}_{3} \mathrm{O}_{4}$ nanoparticles that were obtained by soil centrifugation. When the xerogel was heated to 150 ${ }^{\circ} \mathrm{C}$, a slight increase in $\gamma-\mathrm{Fe}_{2} \mathrm{O}_{3}$ size formed. However, direct drying at $150{ }^{\circ} \mathrm{C}$ of the wet $\mathrm{Fe}_{3} \mathrm{O}_{4}$ gel allowed for the first time to transform into $\alpha-\mathrm{Fe}_{2} \mathrm{O}_{3}$ with a size of $10.1 \mathrm{~nm}$. The XRD models of the samples were measured with a diffractometer, the size of the crystallite was calculated using the Scherrer equation. The observation of the particle morphology was performed on a transmission electron microscope. The powder sample was carefully ground, then dispersed in ethanol by ultrasound. In the case of $\mathrm{Fe}_{3} \mathrm{O}_{4}$, the particles contained on the copper grid were introduced into the TEM test chamber immediately after the vacuum dried sample, avoiding the oxidation of $\mathrm{Fe}_{3} \mathrm{O}_{4}$. Particle size distributions were obtained by counting approximately 500 nanoparticles from TEM images [37]. The combination of microwave assisted heating with the sol gel method offers a quick and efficient synthesis methodology. For example, the researcher Bilecka together with his collaborators developed iron oxide nanoparticles, $\mathrm{Fe}_{3} \mathrm{O}_{4}$ with dimensions of 5$11 \mathrm{~nm}$ using as an iron acetylacetonate precursor which dissolved in benzyl alcohol and was heated to $170{ }^{\circ} \mathrm{C}$ by radiation exposure with microwave for 12 $\min [38]$.

Table 4 illustrates precursors, hydrolysis agents, reaction parameters, characterization methods, dimensions and morphologies of iron oxides obtained by the sol-gel method.

Table 4. Precursors, hydrolysis agents, reaction parameters and characterization of iron oxide nanoparticles obtained by sol-gel method

\begin{tabular}{|c|c|c|c|c|c|c|}
\hline Oxide type & Precursor & $\begin{array}{c}\text { Hydrolysis } \\
\text { agent } / \\
\text { surfactant } / \\
\text { solvent }\end{array}$ & $\begin{array}{c}\text { Temperature } \\
\text { Time }\end{array}$ & $\begin{array}{c}\text { Dimension/ } \\
\text { morphology }\end{array}$ & $\begin{array}{c}\text { Characterization } \\
\text { method }\end{array}$ & References \\
\hline $\mathbf{F e}_{3} \mathbf{O}_{4}$ & $\begin{array}{c}\text { Iron } \\
\text { acetylacetonate }\end{array}$ & $\begin{array}{c}\text { Benzyl } \\
\text { alcohol }\end{array}$ & $12 \mathrm{~min}$ & $\begin{array}{c}11 \mathrm{~nm} \\
7 \mathrm{~nm} \\
5 \mathrm{~nm} / \mathrm{spheres}\end{array}$ & $\begin{array}{c}\text { SEM, TEM, XRD } \\
\text { XRD }\end{array}$ & [37] \\
\hline $\begin{array}{c}\mathbf{F e}_{3} \mathbf{O}_{4} \\
\boldsymbol{\alpha}-\mathbf{F e}_{2} \mathbf{O}_{3} \\
\boldsymbol{\gamma}-\mathbf{F e}_{2} \mathbf{O}_{3}\end{array}$ & $\mathrm{FeCl}_{2} \cdot 4 \mathrm{H}_{2} \mathrm{O}$ & ethanol & $150^{\circ} \mathrm{C}$ & $10.1 \mathrm{~nm} / \mathrm{spheres}$ & SEM, XRD & {$[38]$} \\
\hline
\end{tabular}




\subsection{Ultrasonic assisted hydrolytic synthesis}

This method has been applied for the synthesis of various iron oxide nanoparticles. For example, magnetite can be produced by sonication of iron (II) acetate in water in an argon atmosphere.

Vijayakumar et al. have reported the synthesis of pure nanometric particles of $\mathrm{Fe}_{3} \mathrm{O}_{4}$ using iron (II) acetate as a precursor. $\mathrm{Fe}_{3} \mathrm{O}_{4}$ nano powders made of $10 \mathrm{~nm}$ size are superparamagnetic, and its magnetization at room temperature is very low around $1.25 \mathrm{~g}$ emu 1. The nanoparticles were characterized by elemental analysis, EDX, transmission electron microscopy, dynamic light scattering, Raman spectroscopy, XPS [39].

Amir et al. have developed the $\alpha-\mathrm{Fe}_{2} \mathrm{O}_{3}$ nanocrystalline iron oxide using ultrasound irradiation for 1 hour using a suspension containing hexahydrated iron chloride and aqueous sodium hydroxide. Iron oxide nanoparticles were characterized by TEM, XRD. From TEM observations, the size of iron oxide nanoparticles is estimated to be significantly less than $19 \mathrm{~nm}$. The powder X-ray diffraction data after annealing provide direct evidence that iron oxide formed during the sono-chemical process. They pointed out that highenergy ultrasound use produces spherical particles.
The crystallite size varies between $5 \mathrm{~nm}$ and $7.5 \mathrm{~nm}$ for the different temperatures used. Research shows that the particle size is strongly dependent on the reaction temperature and the ultrasound intensity [40].

The $\alpha-\mathrm{Fe}_{2} \mathrm{O}_{3}$ nanoparticles (hematite) were synthesized by the sono-chemical method by Azadeh at el. who have started from the precursors of iron acetate or iron chloride and sodium hydroxide with molar ratios of $1: 2$ or, respectively, $1: 3$, in $100 \mathrm{~mL}$ ethanol and water at a ratio of 1:3. The reactions were performed with ultrasound (with a frequency of 20 $\mathrm{kHz}$ and a power of approximately $150 \mathrm{~W}$ ) at room temperature for $1 \mathrm{~h}$. In all reactions, the intermediate was $\mathrm{FeO}(\mathrm{OH})$ nanoparticles. The precipitates were then calcined at $900{ }^{\circ} \mathrm{C}$ in an air atmosphere for 4 hours. XRD, SEM and IR spectroscopy were used to characterize the nanostructures. XRD data revealed a rhombohedral (hexagonal) structure with space group $\mathrm{R}-3 \mathrm{c}$ in all samples. TEM and SEM were confirmed by the uniform spherical morphology. The result revealed that the particle sizes varied between 13.02 $\mathrm{nm}$ and $79.197 \mathrm{~nm}$ [41]. Table 5 illustrates precursors, hydrolysis agents, reaction parameters, characterization methods, dimensions of iron oxides obtained by ultrasound.

Table 5. Precursors, hydrolysis agents, reaction parameters and characterization of iron oxide nanoparticles obtained by US method

\begin{tabular}{|c|c|c|c|c|c|c|}
\hline $\begin{array}{c}\text { Oxide } \\
\text { type }\end{array}$ & Precursor & $\begin{array}{c}\text { Hydrolysis } \\
\text { agent } / \\
\text { surfactant } / \\
\text { solvent }\end{array}$ & $\begin{array}{c}\text { Temperature } \\
\text { Time }\end{array}$ & $\begin{array}{c}\text { Dimension/ } \\
\text { morphology }\end{array}$ & $\begin{array}{c}\text { Characterization } \\
\text { method }\end{array}$ & References \\
\hline $\mathrm{Fe}_{3} \mathrm{O}_{4}$ & $(\mathrm{AcCOO})_{3} \mathrm{Fe}$ & $\mathrm{H}_{2} \mathrm{O}$ & $\begin{array}{c}25^{\circ} \mathrm{C} \\
3 \mathrm{~h}\end{array}$ & $10 \mathrm{~nm}$ & $\begin{array}{c}\text { SEM, TEM, XRD, } \\
\text { DLS }\end{array}$ & {$[39]$} \\
\hline $\begin{array}{c}\mathrm{Fe}_{3} \mathrm{O}_{4} \\
\alpha-\mathrm{Fe}_{2} \mathrm{O}_{3} \\
\gamma-\mathrm{Fe}_{2} \mathrm{O}_{3}\end{array}$ & $\mathrm{FeCl} \cdot 6 \mathrm{H}_{2} \mathrm{O}$ & $\mathrm{NaOH}$ & $1 \mathrm{~h}$ & $19 \mathrm{~nm} /$ spheres & SEM, XRD & {$[40]$} \\
\hline$\alpha-\mathrm{Fe}_{2} \mathrm{O}_{3}$ & $\begin{array}{c}\mathrm{Fe}\left(\mathrm{C}_{2} \mathrm{H}_{3} \mathrm{O}_{2}\right)_{2} \\
\mathrm{sau}_{2}\end{array}$ & $\mathrm{FaOH}$ & $\begin{array}{c}150 \mathrm{~W} \\
20 \mathrm{KHz}\end{array}$ & $\begin{array}{c}13.02 \mathrm{~nm}- \\
79.197 \mathrm{~nm} / \\
\text { spheres }\end{array}$ & SEM, XRD, IR & {$[41]$} \\
\hline
\end{tabular}

\section{Conclusions}

From the analysis of the specialized scientific works regarding the elaboration and characterization of the iron oxide with catalytic applications, important elements regarding: the type of the synthesis, the methods of morpho-structural characterization have resulted.

Based on the analysis regarding the researches carried out on the synthesis and characterization of iron oxide, the following conclusions were drawn. Magnetite, $\mathrm{Fe}_{3} \mathrm{O}_{4}$, exhibits the strongest magnetism of transition metal oxides. Hematite, $\alpha-\mathrm{Fe}_{2} \mathrm{O}_{3}$, being the most stable oxide and semiconductor type $\mathrm{n}$ under environmental conditions, can be widely used in catalysts, pigments and gas sensors. Iron oxide nanoparticles $\left(\mathrm{Fe}_{3} \mathrm{O}_{4}\right.$ and $\left.\gamma-\mathrm{Fe}_{2} \mathrm{O}_{3}\right)$ with superparamagnetic properties and low toxicity, are particularly useful for catalytic applications especially in the medical field, such as magnetic resonance imaging (MRI). For these applications, the $\mathrm{Fe}_{3} \mathrm{O}_{4}$ and $\gamma-\mathrm{Fe}_{2} \mathrm{O}_{3}$ nanoparticles are usually smaller than $20 \mathrm{~nm}$, where they have superparamagnetic properties, i.e. a high magnetic saturation moment and almost zero coercivity. Various morphologies of iron oxide 
nanoparticles (nanospheres, plates, tetrahedra, cubes, nanowires, nanotubes, nanoflores, nanoins) have been elaborated according to different synthesis protocols. Methods for the production of titanium dioxide include chemical syntheses (hydrothermal, sol-gel, co-precipitation, sonochemistry, microwave assisted) using a variety of precursors of $\mathrm{Fe}^{2+}, \mathrm{Fe}^{3+}$ salts (chlorides, sulphates, acetates, nitrates). The size of the iron oxide nanoparticles elaborated by the coprecipitation method varies from $3 \mathrm{~nm}$ to $82 \mathrm{~nm}$. The size of the iron oxide nanoparticles synthesized by the thermal decomposition method varies from $4 \mathrm{~nm}$ to $30 \mathrm{~nm}$. By the sol gel method, iron oxide nanoparticles were obtained, the size of which varies from $5 \mathrm{~nm}$ to $11 \mathrm{~nm}$. The size of iron oxide nanoparticles elaborated by the sonochemistry method ranges from $10 \mathrm{~nm}$ to $79.197 \mathrm{~nm}$. Iron oxide nanoparticles were characterized by transmission electron microscopy, X-ray diffraction, IR spectroscopy with Fourier transform.

\section{References}

[1]. Moura K. F., Maul J., Albuquerque A. R., Casali G. P., Longo E., Keyson D., Souza A. G., Sambrano J. R., I.M.G. J. Solid State Chem, 210, p. 171-177, 2014.

[2]. Babay S., Mhiri T., Toumi M., J Mol Struct, 1085, p. 286293, 2015

[3]. Machala L., Tucek J., Zboril R., Chem Mater, 23, (14), p. 3255-3272, 2011.

[4]. Zhang Z., Boxall C., Kelsall G. H., Colloids Surf., A 73, 145, 1993.

[5]. Wu W., Xiao X. H., Zhang S. F., Zhou J. A., Fan L. X., Ren F., Jiang C. Z., J. Phys. Chem. C, 114, 16092, 2010.

[6]. Teja S. A., Koh P. Y., Prog Cryst Growth Charact Mater, 55 , p. 22-45, 2009

[7]. Boxall C., Kelsall G., Zhang Z., J. Chem. Soc. Faraday Trans, 92, 79, 1996.

[8]. Wei Wu., Zhaohui Wu., Taekyung C. J., Woo S. K., Sci Technol Adv Mat, 16, 43, 2015.

[9]. Cullity B. D., AddisonWesley: Reading, MA., p. 9-80, 1972.

[10]. Salata O. V., J Nanobiotechnology, 2, 3, 2004.

[11]a. Jiang J. Z, Lin R., Lin W., Nielsen K., Mørup S., Dam Johansen K., Clasen R., J. Phys, 30, 1459, 1997.

[11]b. Sun H. T., Cantalini C., Faccico M., Peline M., J. Am. Ceram. Soc., 79, 927, 1996.

[11]c. Matijevic E., Scheiner P. J., Colloid Interface Sci., 63, 509, 1978 .

[11]d. Ozaki M., Kratohvil S., Matijevic B., J. Colloid Interface Sci., 102, 146, 1984.

[12]a. Benz M., van der Kraan A. M., Prins. R, J. Appl. Catal. A., 172, 149, 1998.

[12]b. Anantharaman M. R., Joseph K. V., Keer H. V., Bull, Mater. Sci., 20, 975, 1997.

[12]c. Kryder M. H., MRS Bull 21, 17, 1996.

[12]d. Onodera S., Kondo H., Kawana T., MRS Bull, 21, 35, 1996.

[12]e. Watanabe H., Seto J., Bull. Chem. Soc. Jpn 61, 2411, 1991. [12]f. Hong F. B., Yang L., Schwartz L. H., Kung H. H., J. Phys. Chem., 88, 2525, 1984. [13]a. Lubbe A. S., Bergemann C., Brock F., McClure D. G., J. Magn. Magn. Mater, 194, 149, 1999.

[13]b. Popplewell J., Sakhnini L., J. Magn. Magn. Mater, 149,72, 1995.

[13]c. Pouliquen D., Perroud H., Calza F., Jallet P., Lejeune. J. Magn. Reson. Med., 24, 75, 1992.

[13]d. Lisiecki I., Billoudet F., Pileni M. P., J. Phys. Chem, 100, 4160, 1996.

[14]. Hibst H., Schwab E., Cahn R. W., VCH, Weinheim, 3B, 352, 1993.

[15]. Azhar Uddin M., Tsuda H., Wu S., E. Sasaoka 87, 451-459, 2008 .

[16]. Li C., Shen Y., Jia M., Sheng S., Adebajo M. O., Zhu H., 9, 355-361, 2008

[17]. Shi F., Tse M. K., Pohl M. M., Bruckner A., Zhang S. M., Beller M., Angewandte Chemie International Edition, 46, 88668868, 2007.

[18]. Bautista F. M., Campelo J. M., Luna D., Marinas J. M., Quiros R. A., Romero A. A., Applied Catalysis B: Environmental, 70, p. 611-620, 2007.

[19]. Frank J. Owens, Charles P. Poole Jr., The Physics and Chemistry of Nanosolids, p. 1-40, 2009.

[20]. Wu W., He Q., Jiang C., Nanoscale Res Lett., 3:397, 2008.

[21]. ***, Nanocrystals. Nat Mater., 3:891, 2004.

[22]. Zhou Z., Zhu X., Wu Park J., An K., Hwang Y., Park J.G., Noh H.-J., Kim J.-Y. et al., Chem. Mater., 27, p. 3505-3515, 2015.

[23]. Roh Y., Vali H., Phelps T. J., Moon J. W., J Nanosci Nanotechnol, 6, p. 3517-3520, 2006.

[24]. Bharde A. A., Parikh R. Y., Baidakova M., Jouen S., Hannoyer B., Enoki T., et al., Langmuir, 24, p. 5787-5794, 2008.

[25]. Aftabtalab A., Sadabadi H., Chakra C. S., Rao K. V., Sarah Shaker, Mahofa E. P., IJSER, 5, p. 1419-1423, 2014.

[26]. Massart R., 17, p. 1247-1248, 1981.

[27]. Laurent S., Forge D., Port M. Rev. Chem. Eng., 108, p. 2064-2110, 2008.

[28]. Sun S., Zeng H., J Am Chem Soc. 124, p. 8204-8205, 2002.

[29]. Kang Y. S., Risbud S., Rabolt J. F., Stroeve P. Chem., 8, p. 2209-2211, 1996.

[30]. Ahn T., Kim J. H., Yang H.-M., Lee J. W., Kim J.-D., J. Phys. Chem. C., 116, p. 6069-6076, 2012.

[31]. Lenders J. J. M., Altan C. L., Bomans P. H. H., Arakaki A., Bucak S., de With G. Sommerdijk, N.A.J.M., 14, p. 55615568, 2014.

[32]. Abdelmajid L., Brahim D., Abdellatif G., Salah A., Results in Physics, 7, p. 3007-3015, 2017.

[33]. Khalil M. I., Arab J. Chem., 8, p. 279-284, 2015

[32]. Rockenberger J., Scher E. C., Alivisatos A. P., J. Am. Chem. Soc., 121, p. 11595-11596, 1999.

[33]. Park J., An K., Hwang Y., Park J. G., Noh H. J., Kim J. Y., Park J. H., Nat. Mater., 3, p. 891-895, 2004.

[34]. Maity D., Choo S.-G., Yi J., Magn Magn Mater., 32, p. 1256-1259, 2009.

[35]. Yu W. W., Falkner J. C., Yavuz C. T., Colvin V. L., Chem. Commun, p. 2306-2307, 2004.

[36]. Sun S., Zeng H., J. Am. Chem. Soc., 124, 8204, 2000.

[37]. Cui H., Liu Y., Ren W., Adv. Powder Technol., 24, p. 93-97, 2013.

[38]. Bilecka I., Djerdj I., Niederberger M., Chem Commun., p. 886-888, 2008.

[39]. Vijayakumar R., Koltypin Y., Felner I., Gedanken A., Mater. Sci. Eng., 286, p. 101-105, 2000.

[40]. Amir Hassanjani-Roshana, Mohammad Reza Vaezi, Ali Shokuhfar, Zohreh Rajabali, Particuology, 9, p. 95-99, 2011.

[41]. Azadeh A., Mojtaba B., Morsali A., J Exp Nanosci, 6, p. 217-225, 2011. 